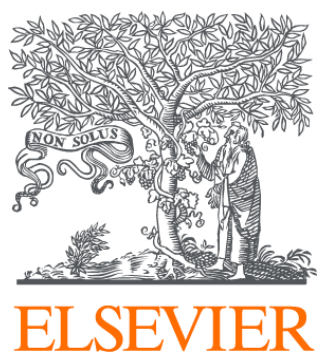

Since January 2020 Elsevier has created a COVID-19 resource centre with free information in English and Mandarin on the novel coronavirus COVID-

19. The COVID-19 resource centre is hosted on Elsevier Connect, the company's public news and information website.

Elsevier hereby grants permission to make all its COVID-19-related research that is available on the COVID-19 resource centre - including this research content - immediately available in PubMed Central and other publicly funded repositories, such as the WHO COVID database with rights for unrestricted research re-use and analyses in any form or by any means with acknowledgement of the original source. These permissions are granted for free by Elsevier for as long as the COVID-19 resource centre remains active. 


\title{
The potential of molecular diagnostics and serum procalcitonin levels to change the antibiotic management of community-acquired pneumonia
}

\author{
David Gilbert* , Gita Gelfer, Lian Wang, Jillian Myers, Kristina Bajema, Michael Johnston, James Leggett \\ Providence Portland Medical Center, Portland, OR, USA
}

\section{A R T I C L E I N F O}

\section{Article history:}

Received 19 April 2016

Received in revised form 7 June 2016

Accepted 8 June 2016

Available online 15 June 2016

Keywords:

Community-acquired pneumonia

\begin{abstract}
A B S T R A C T
Two diagnostic bundles were compared in 127 evaluable patients admitted with community-acquired pneumonia (CAP). Diagnostic modalities in all patients included cultures of sputum (if obtainable) and blood, urine for detection of the antigens of Streptococcus pneumoniae and Legionella pneumophila, and nasal swabs for PCR probes for S. pneumoniae and Staphylococcus aureus. At least one procalcitonin level was measured in all patients. For virus detection, patients were randomized to either a 5-virus, lab-generated PCR panel or the broader and faster FilmArray PCR panel.

Overall, an etiologic diagnosis was established in $71 \%$ of the patients. A respiratory virus was detected in $39 \%$. The potential for improved antibiotic stewardship was evident in 25 patients with only detectable respiratory virus and normal levels of PCT.
\end{abstract}

(c) 2016 Elsevier Inc. All rights reserved.

\section{Introduction}

Community-acquired pneumonia (CAP) is a common and potentially lethal infectious disease that requires concomitant attempts to determine a microbial etiology and the prompt initiation of broad spectrum empiric antibacterials (Mandell et al., 2007).

Our study was designed to: optimize the rapid detection of pathogenic bacteria and/or viruses; use normal serum procalcitonin (PCT) levels to exclude the presence of invasive bacteria; provide the microbiologic and PCT data to clinicians within 48 hours or less of admission; and determine if physician providers would respond to the data provided by switching from empiric to either no therapy (non-influenza viral illness) or a directed specific antimicrobial regimen.

The protocol described herein is the same used during January to March, 2014 (Gelfer et al., 2015), enrolling an additional 127 patients during the 2014-2015 winter months.

\section{Materials and methods}

\subsection{Study conduct and design}

\subsubsection{Study conduct}

This study was conducted as a non-blinded cluster randomization trial at a 480 bed community-teaching hospital in Portland Oregon (Providence Portland Medical Center-PPMC). The project was approved by both the Institutional Review Board (IRB) and the Privacy Board of

\footnotetext{
* Corresponding author. Tel: +1-503-215-6260; fax: +1-503-215-0450.

E-mail address: david.gilbert@providence.org (D. Gilbert).
}

PPMC. Only de-identified chart data was collected; the IRB indicated no need for informed consent.

Prior to study initiation, the investigators reviewed the study protocol with Emergency Department nurses, physicians, hospitalists, residents, and clerks.

A diagnosis of CAP requiring admission made by ED physicians prompted enrollment in the study. The ED physician ordered protocolmandated diagnostic "bundles" which were initiated by ED nurses, who also ordered empiric antibiotic therapy. ED unit clerks notified investigators of a new patient. The protocol neither dictated nor suggested antibiotic management to either the ED or inpatient physicians.

Providers learned of test results via the electronic medical record (EMR), with two exceptions. Providers were notified immediately of positive blood cultures or identification of influenza.

\subsubsection{Study design}

A common core of diagnostic tests was applied to all patients in the study: i.e., two blood cultures, sputum culture and sensitivity, serum PCT level, urine antigen testing for Legionella pneumophila, serogroup 1 and Streptococcus pneumoniae, nasal swabs for PCR detection of the lyt gene of S. pneumoniae and Staphylococcus aureus. S. aureus PCR (BD Max Staph SR) was purchased from Becton-Dickinson.

PCT levels were determined using an immunoassay (bioMerieux) performed on a Vidas system. The protocol called for only one baseline PCT serum level; providers ordered additional PCT levels at their discretion. PCT results included an interpretative algorithm modeled after a widely-used used European format (Schuetz et al., 2012, 2013). Values below $0.1 \mathrm{ng} / \mathrm{mL}$ were interpreted as "bacterial etiology very unlikely"; values $>0.25-0.5 \mathrm{ng} / \mathrm{mL}$ as "bacterial etiology likely"; and values $>0.5 \mathrm{ng} / \mathrm{mL}$ as "bacterial etiology very likely". The algorithm suggests 
a repeat PCT level in 4-6 hours in those patients with levels $\leq 0.25 \mathrm{ng} / \mathrm{mL}$ and possible evolving bacterial infection.

In addition to the common bundle, patients were cluster-randomized in one week blocks to undergo additional diagnostic testing with either the PPMC laboratory-generated respiratory pathogen PCR panel (Standard) or a commercial multiplex PCR panel (FilmArray), from Biofire (Salt Lake City, UT).The Standard panel probes for influenza $A$ and $B$, adenovirus, human metapneumovirus, respiratory syncytial virus, and rhinovirus. Specimens were run daily at least 6 days per week; results were available within 12-48 hours. On alternate weeks, nasaopharyngeal (NP) swabs were processed with FilmArray, that probes for five types of influenza, four types of parainfluenza, rhinovirus/ enterovirus, adenovirus, human metapneumovirus, four types of coronavirus, respiratory syncytial virus, Mycoplasma pneumoniae, Chlamydophila pneumoniae, and Bordetella pertussis.

\subsubsection{Data collection}

The authors extracted data from the patients' EMR, using an assigned study number and database file (Filemaker, Pro 13). Data extraction began at enrollment, continued periodically during hospitalization, and was completed post-discharge. All data entry was verified by two or three of the authors.

Infectious diseases pharmacists entered data referable to use of antibacterial and/or anti-influenza therapy. Using a standardized list of the purchase expense of individual antibiotics, one investigator (DNG) determined the days of, and expense of, antimicrobial therapy. On any given day, empiric therapy with 3 different antibiotics, regardless of the number of doses, was defined as 3 days of therapy (DOT). The length, or number of days, of therapy (LOT), regardless of the number of drugs administered each day, was also calculated. Results were normalized to 1000 hospital patient-days.

\subsection{Inclusion and exclusion criteria}

Inclusion required an ED diagnosis of CAP of sufficient severity to require hospitalization in a patient 18 years of age or older. Patients were excluded if it was not possible to obtain a NP swab or if antibiotics were withheld and comfort care initiated. Post-enrollment, patients were excluded if two sites of infection were present: e.g., CAP plus a non-CAP infection, if patients were placed on comfort care with discontinuation of anti-infectives, or if there was a failure to collect the protocolmandated diagnostic tests. Patients unable to provide an acceptable sputum for culture were not excluded.

\subsection{Final clinical categorization}

The final database for each enrolled patient was reviewed by two of the investigators (JL and DNG) for the purpose of final categorization as per the definitions below. In the event of disagreement, adjudication was by a third investigator (GG). The criteria for the assigned final clinical diagnosis were:

\subsubsection{Uninfected; no evidence of CAP}

Post-admission clinical, laboratory and imaging studies document an alternative non-infectious diagnosis: e.g., congestive heart failure.

\subsubsection{Bacterial pneumonia}

Proven: Pulmonary infiltrates and a bacterial pathogen in sputum, blood, or pleural fluid; a positive S. pneumoniae NP swab PCR and/or S. pneumoniae urine antigen was accepted as bacterial pneumonia.

Presumptive: Multifocal pulmonary infiltrates and detection of S. pneumoniae or S. aureus by PCR of a nasal swab in patients in whom it was not possible to obtain sputum or a bronchoalveolar lavage specimen. Elevation of the serum procalcitonin was used as evidence of bacterial invasion as opposed to asymptomatic colonization.
In the presence of clinical pneumonia, a serum procalcitonin level of $\geq 0.25 \mathrm{ng} / \mathrm{mL}$ was accepted as presumptive evidence of bacterial pneumonia in the absence of detection of a bacterial pathogen; e.g., the patient with documented aspiration.

\subsubsection{Viral pneumonia}

Presumptive: Identification of the presence of adenovirus, coronavirus, human metapneumovirus, influenza, parainfluenza, respiratory syncytial virus, or rhinovirus by one of the PCR probes and a compatible clinical syndrome. In distinction to potential bacterial pathogens like S. aureus and S. pneumoniae, asymptomatic nasal colonization by respiratory viral pathogens is a rare occurrence.

\subsubsection{Bacterial-viral co-infected}

Presumptive: Respiratory virus detected and either serum PCT was above $0.5 \mathrm{ng} / \mathrm{mL}$, and/or a bacterial pathogen found in a sputum culture, by urine antigen, or PCR. Bacterial and viral pathogens were identified as "potential" etiologic agents as no seroconversion studies were performed.

\subsection{Determination of protocol adherence of patient data}

Each patient file was reviewed by three investigators (GG, JL, DG). A patient was considered evaluable only if all protocol-required diagnostic studies were performed, except for sputum culture if no sputum could be obtained. Each patient file was reviewed to determine if the patient's pneumonia diagnosis was, in hindsight, correct. Of those patients with a clinical pneumonia syndrome, the investigators classified the etiology of the pneumonia in one of 4 ways: viral, bacterial, or a combination of viral and bacterial, or, when no pathogen was found, clinical pneumonia of unclear etiology. If a respiratory virus was detected, an associated bacterial infection was deemed present if a bacterial pathogen was identified by culture PCR or urine antigens, or if the serum PCT concentration was $>0.5 \mathrm{ng} / \mathrm{mL}$.

\subsection{Statistics}

For comparisons between the two diagnostic methods, $t$ test or Wilcoxon test was performed for continuous variables, and chi-square test or Fisher's Exact test was performed for categorical variables. Kruskal-Wallis test or one-way ANOVA test was used for comparisons among the three distinct etiology groups (viral, bacterial, or a combination of viral and bacterial).

\section{Results}

From December 4, 2014, to March 6, 2015, the ED admitted 211 patients with a diagnosis of CAP (Fig. 1). Of the 99 patients randomized to the Standard group, 31 patients were non-evaluable, due to inadequate evidence of pneumonia in 26, incomplete diagnostics in 3 , and transition to comfort care within a day in 2 patients. Inadequate evidence of pneumonia was attributable to patients with bronchitis or COPD exacerbation (8), sepsis from another source (7), CHF (5), cystic fibrosis (2), metastatic cancer (2), MAI (1) and chemical aspiration (1). Of the remaining 68 evaluable patients, 1 or more pathogens were identified in 47 (69\%).

Of the 111 patients randomized to the FilmArray group, 52 patients were non-evaluable, due to inadequate evidence of pneumonia in 40 , incomplete diagnostics in 3, and transition to comfort care in 9 patients within a day. Inadequate evidence of pneumonia was attributable to patients with bronchitis or COPD exacerbation (13), sepsis from another source (12), CHF (6), metastatic cancer (6), asthma, pulmonary embolism, or chemical aspiration ( 1 each). Of the remaining 59 evaluable patients, 1 or more pathogens were identified in 43 (73\%).

Non-evaluable patients were otherwise similar to those evaluable with respect to demographics, comorbidities, and other features listed in Table 1. 


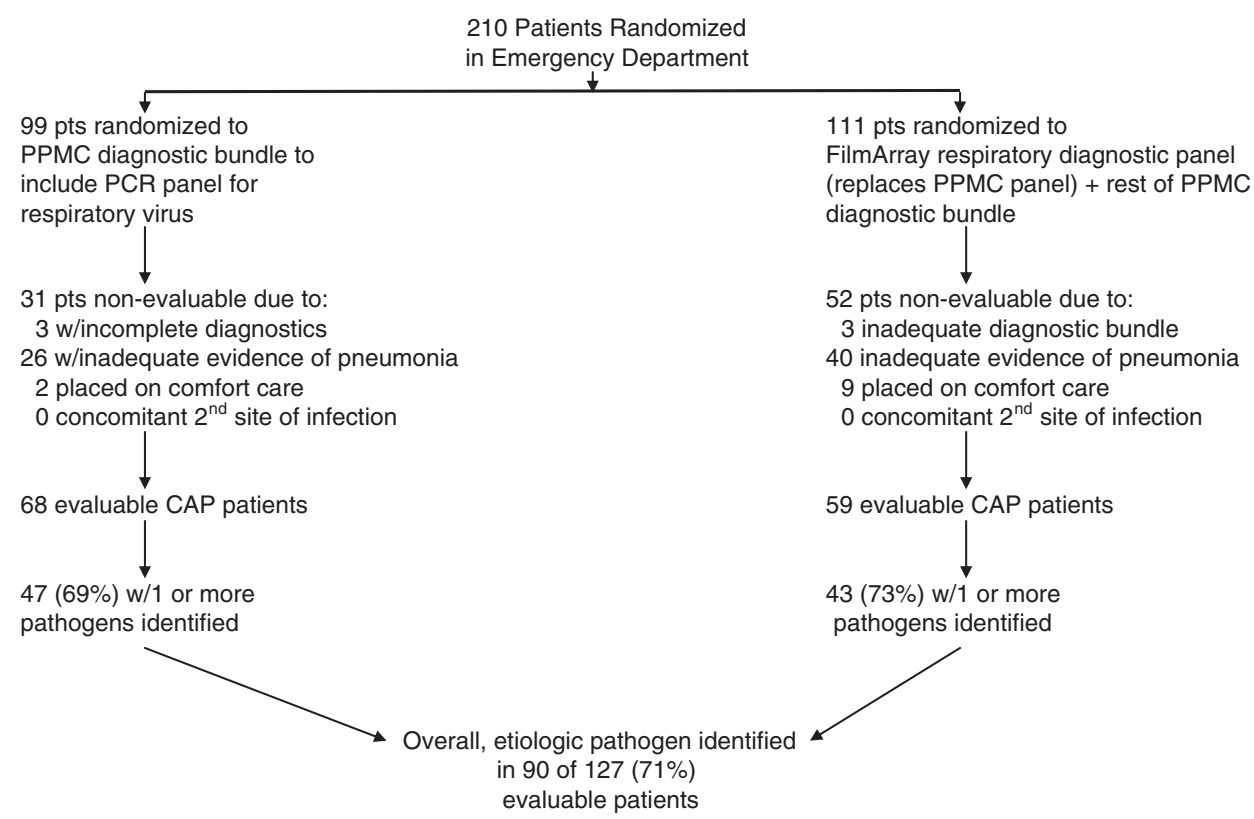

Fig. 1. Screening, eligibility, and enrollment of hospitalized adults with CAP.

\subsection{Patient characteristics}

The demographic and clinical features of the Standard and FilmArray evaluable patients are summarized in Table 1 . The pneumonia severity index (PSI) range results were similar, placing the bulk of the patients in risk group III (scores 71-90) and hence justifying hospitalization. Comorbidities were evenly distributed.

\subsection{Potential microbial etiology of the patients' CAP}

Combining all the evaluable patients in the Standard and FilmArray groups, one or more potential pathogens were detected in 90 of 127

Table 1

Characteristics of evaluable patients.

\begin{tabular}{|c|c|c|c|}
\hline & \multicolumn{2}{|l|}{ Diagnostic group } & \multirow[t]{2}{*}{$P$-value } \\
\hline & $\begin{array}{l}\text { Standard } \\
(\mathrm{n}=68)\end{array}$ & $\begin{array}{l}\text { FilmArray } \\
(\mathrm{n}=59)\end{array}$ & \\
\hline \multicolumn{4}{|l|}{ Demographics } \\
\hline Age, mean \pm SD & $70.9 \pm 17.9$ & $69.9 \pm 17.7$ & 0.75 \\
\hline Male sex (\%) & $36(52.9 \%)$ & $26(44.1 \%)$ & 0.41 \\
\hline Weight $(\mathrm{kg})$, mean $\pm \mathrm{SD}$ & $75.8 \pm 23.3$ & $76.7 \pm 29.6$ & 0.84 \\
\hline \multicolumn{4}{|l|}{ Clinical features } \\
\hline Highest temperature $\left({ }^{\circ} \mathrm{C}\right)$ in $1 \mathrm{st} 24 \mathrm{hr}$ & $37.9 \pm 0.9$ & $37.8 \pm 0.9$ & 0.84 \\
\hline WBC, total & $16,661 \pm 15.617$ & $14,612 \pm 6,992$ & 0.33 \\
\hline Pneumonia severity index & $78.4 \pm 13.4$ & $81.8 \pm 11.4$ & 0.12 \\
\hline \multicolumn{4}{|l|}{ Comorbidity and habits } \\
\hline Alcoholism & $3(4.4 \%)$ & $5(8.5 \%)$ & 0.47 \\
\hline Alcohol use, current & $10(14.7 \%)$ & $11(18.6 \%)$ & 0.72 \\
\hline Congestive heart failure & $12(17.6 \%)$ & $14(23.7 \%)$ & 0.53 \\
\hline COPD & $25(36.8 \%)$ & $20(33.9 \%)$ & 0.88 \\
\hline Diabetes mellitus & $21(30.9 \%)$ & $20(33.9 \%)$ & 0.86 \\
\hline HIV & $3(4.4 \%)$ & $1(1.7 \%)$ & 0.62 \\
\hline Illicit drug use & $4(5.9 \%)$ & $8(13.6 \%)$ & 0.24 \\
\hline Liver disease, chronic & $6(8.8 \%)$ & $9(15.3 \%)$ & 0.4 \\
\hline Malignancy & $8(11.8 \%)$ & $6(10.2 \%)$ & 0.9 \\
\hline Obstructive sleep apnea & $6(8.8 \%)$ & $7(11.9 \%)$ & 0.9 \\
\hline Renal insufficiency & $21(30.5 \%)$ & $19(32.2 \%)$ & 0.9 \\
\hline Tobacco use, current & $16(23.5 \%)$ & $13(22 \%)$ & 0.9 \\
\hline \multicolumn{4}{|l|}{ Home medications } \\
\hline Antibiotics & $8(11.8 \%)$ & $6(10.2 \%)$ & 0.9 \\
\hline Glucocorticoids & $9(13.2 \%)$ & $7(11.9 \%)$ & 0.9 \\
\hline Narcotics & $28(41.2 \%)$ & $15(25.4 \%)$ & 0.09 \\
\hline PPI/H2 blocker & $21(30.9 \%)$ & $26(44.1 \%)$ & 0.18 \\
\hline
\end{tabular}

(71\%) patients. In 40 of 127 (32\%) only a potential bacterial pathogen was found; in 25 of 127 (20\%) only a potential viral pathogen was detected; and in 24 of 127 (19\%) both viral and bacterial pathogens were found. No statistical differences in diagnostic yield existed between Standard and FilmArray patients. In the remaining 37 patients (29\%) with CAP, no potential pathogen was found.

Sputum for culture was only obtainable in 74 of the 127 (58\%) evaluable patients. A candidate bacterial pathogen was found in only 28 of 127 (22\%) patients, Table 2 . S. pneumoniae was identified in only 5 sputa (3.9\%). Both $H$. influenzae and S. aureus were cultured in 9 (7\%) patients. Two patients were bacteremic (1.6\%), both due to S. pneumoniae; S. pneumoniae antigen was detected in the urine of both patients. The urine antigen test for $S$. pneumoniae was positive in 16 of 127 (13.5\%) patients. No patients had a positive urine antigen test for L. pneumophila.

The S. pneumoniae NP PCR was positive in 24 of 127 (18.9\%) of patients, Table 2 , but in only 10 of the 24 was the concomitant urine antigen test positive.

Table 2

Diagnostic yield for bacteria with selected test methods.

\begin{tabular}{lllll}
\hline & Standard & FilmArray & Total & \% Total \\
\hline $\begin{array}{l}\mathrm{n}=\text { number evaluable patients } \\
\text { Sputum }\end{array}$ & 68 & 59 & 127 & \\
$\quad$ No. pts w/sputum cultures & 38 & 36 & 74 & $58 \%$ \\
$\quad$ \# positive for potential pathogen & 14 & 14 & 28 & $22 \%$ \\
$\quad$ \# positive for S. pneumoniae & 3 & 2 & 5 & $3.9 \%$ \\
$\quad$ \# positive for H. influenzae & 4 & 5 & 9 & $7 \%$ \\
$\quad$ \# positive for S. aureus & 4 & 5 & 9 & $7 \%$ \\
Blood & & & & \\
$\quad$ No. pts w/blood cultures & 68 & 59 & 127 & \\
$\quad$ \# positive & 1 & 1 & 2 & $1.6 \%$ \\
Urine & & & & \\
$\quad$ No. pts w/antigens done & 68 & 59 & 127 & \\
$\quad$ No. pts w/positive Legionella antigen & 0 & 0 & 0 & \\
$\quad$ No. pts w/positive S. pneumoniae antigen & 6 & 10 & 16 & $12.5 \%$ \\
Nasal PCR & & & & \\
$\quad$ \# S. pneumoniae positive & $13^{*}$ & $11^{*}$ & $24^{*}$ & $18.9 \%$ \\
$\quad$ \# S. aureus positive & $9^{\dagger}$ & $11^{\dagger}$ & $20^{\dagger}$ & $16.0 \%$ \\
\hline
\end{tabular}

* Of the total of 24 patients with a positive NP swab PCR for S. pneumoniae, 10 had concomitant positive tests for $S$. pneumonia urine antigen.

${ }^{\dagger}$ Of the total 20 patients with a positive nasal swab PCR for S. aureus, 9 had concomitant positive sputum cultures. 
Table 3

Comparison of potential etiologic pathogens detected by PPMC standard diagnostic bundle or diagnostic bundle with FilmArray multiplex PCR substituted for PPMC viral PCR respiratory virus panel.

\begin{tabular}{lcc}
\hline Pathogen identified & Standard & FilmArray \\
& $(47$ pts $)$ & $(43$ pts $)$ \\
\hline Patients with viral pathogen only: Subtotal & $\mathbf{1 3}$ & $\mathbf{1 2}$ \\
- Adenovirus & 0 & 0 \\
- Coronavirus & 0 & 1 \\
- Human metapneumovirus & 1 & 1 \\
- Influenza & 11 & 5 \\
- Parainfluenza & 0 & 1 \\
- Respiratory syncytial virus & 0 & 4 \\
- Rhinovirus & 1 & 0 \\
Patients with bacterial pathogen only: Subtotal & $\mathbf{2 0}$ & $\mathbf{2 1}$ \\
- S. pneumoniae & 8 & 6 \\
- S. aureus (MSSA + MRSA) & 4 & 6 \\
- S. pneumoniae + S. aureus & 1 & 2 \\
- H. influenzae & 3 & 5 \\
- Streptococcus species & 1 & 1 \\
- Moraxella catarrhalis & 0 & 1 \\
- Enterobacteriaceae species & 3 & 0 \\
Patients with viral and bacterial pathogens: Subtotal & $\mathbf{1 4}$ & $\mathbf{1 0}$ \\
- Virus + elevated procalcitonin serum concentration & 2 & 1 \\
- S. pneumoniae + adenovirus & 0 & 0 \\
- S. pneumoniae + coronavirus & 0 & 0 \\
- S. pneumoniae + hMPV* & 0 & 0 \\
- S. pneumoniae + influenza & 3 & 2 \\
- S. pneumoniae + parainfluenza & 1 & 1 \\
- S. pneumoniae + RSV* & 2 & 2 \\
- S. pneumoniae + rhinovirus & 0 & 1 \\
- S. aureus + hMPV* & 1 & 2 \\
- S. aureus + influenza & 2 & 0 \\
- Streptococcus species + influenza & 1 & 0 \\
- Mixed bacterial flora + influenza & 2 & 1 \\
\hline
\end{tabular}

${ }^{*}$ hMPV $=$ human metapneumovirus; RSV = respiratory syncytial virus.

The S. aureus PCR was positive in 20 of 127 (16\%) patients, in 9 of whom $S$. aureus also grew in sputum culture.

In sum, a potential bacterial pathogen was detected by culture of sputum and/or blood and/or urine antigen and/or PCRs for S. pneumoniae and S. aureus in 78 of 127 (64\%) patients. Viral PCR panels detected a respiratory virus in 49 of the 127 38.6\%) of the patients. In 24 patients, a virus was detected concomitant with a bacterial pathogen, Table 3. Adding the 25 patients with only a respiratory virus to the 65 with a bacterial pathogen detected alone or with a virus, one or more pathogens were identified in 90 of the 127 (71\%) evaluable patients.

\subsection{Comparison of standard versus FilmArray diagnostic bundles}

A viral or bacterial pathogen was identified in 47 patients randomized to the Standard panel and 43 patients randomized to the FilmArray panel, Table 3. In $29 \%$ of the patients with a clinical syndrome of CAP, no pathogen was identified.

No significant differences were noted between the limited PPMC viral diagnostic panel and the expanded FilmArray panel in total number of viruses detected. The number of pathogens and their distribution between Standard and FilmArray patients is presented in Table 3. Influenza was the most common virus detected either alone in 16 patients or in combination with S. pneumoniae (5 patients) or S. aureus (3 patients). S. pneumoniae without a concomitant virus was found in 17 patients and combined with a respiratory virus in 12 patients.

\subsection{Turnaround time}

The turnaround time, to include processing, running, and result reporting for the diagnostic tests is summarized in Table 4. The FilmArray panel turnaround time was a mean of 2.1 hours as compared to the PPMC standard viral panel at a mean of 26.5 hours, $P<0.001$. The urine antigen results were reported in roughly 7-8 hours and the nasal PCRs
Table 4

Turnaround time for diagnostic tests.

\begin{tabular}{lccc}
\hline & $\begin{array}{l}\text { Standard } \\
(\mathrm{n}=68)\end{array}$ & $\begin{array}{l}\text { FilmArray } \\
(\mathrm{n}=59)\end{array}$ & P-value \\
\hline $\begin{array}{l}\text { Sputum culture and sensitivity (h) } \\
\text { Urine antigen: }\end{array}$ & $55.2 \pm 12.5$ & $55.9 \pm 18.5$ & 0.85 \\
$\quad$ & $7.6 \pm 5.3$ & $7.5 \pm 5.8$ & 0.92 \\
$\quad$ S. pneumoniae (h) & $7.9 \pm 6.1$ & $7.3 \pm 5.7$ & 0.63 \\
$\quad$ L. pneumoniae (h) & $130.3 \pm 16.8$ & $132.6 \pm 14.9$ & 0.41 \\
Blood culture (h) & & & \\
Nasopharyngeal swab for: & $26.5 \pm 15$ & $2.1 \pm 0.7$ & $<0.001$ \\
$\quad$ Respiratory virus PCR panels (h) & $27.2 \pm 20.3$ & $32.2 \pm 20.7$ & 0.17 \\
S. pneumoniae PCR (h) & $16.1 \pm 8$ & $17.3 \pm 9$ & 0.44 \\
$\quad$ S. aureus PCR (h) & & &
\end{tabular}

for S. pneumoniae and S. aureus in approximately 30 and 18 hours. Sputum and blood culture results required several days to complete.

\subsection{Serum procalcitonin $(P C T)$ concentrations}

The admission serum PCT concentrations are summarized in Fig. 2. The PCT levels are significantly lower in the patients infected with only a virus versus the patients infected with a bacteria or a combination of a virus and a bacteria, $P<0.003$.

\subsection{Influence of diagnostics on antibacterial therapy}

All enrolled evaluable patients received their first doses of empiric antibiotic therapy within six hours of arrival and before leaving the ED. The LOT, DOT and cost of antibiotics and antivirals (for influenza) were calculated and normalized to 1000 patient-days, Table 5. Overall, the median cost of therapy was lower in FilmArray patients versus standard patients ( $\$ 3037$ vs $\$ 7952, P=0.02$ ). For each etiologic category, the cost was consistently lower for patients in the FilmArray group, but was only significant in patients with combined bacterial and viral pathogens $(P=$ 0.046 ), the highest cost etiologic category. The LOT in virus-only patients was significantly lower than in patients with bacterial infection, $P=$

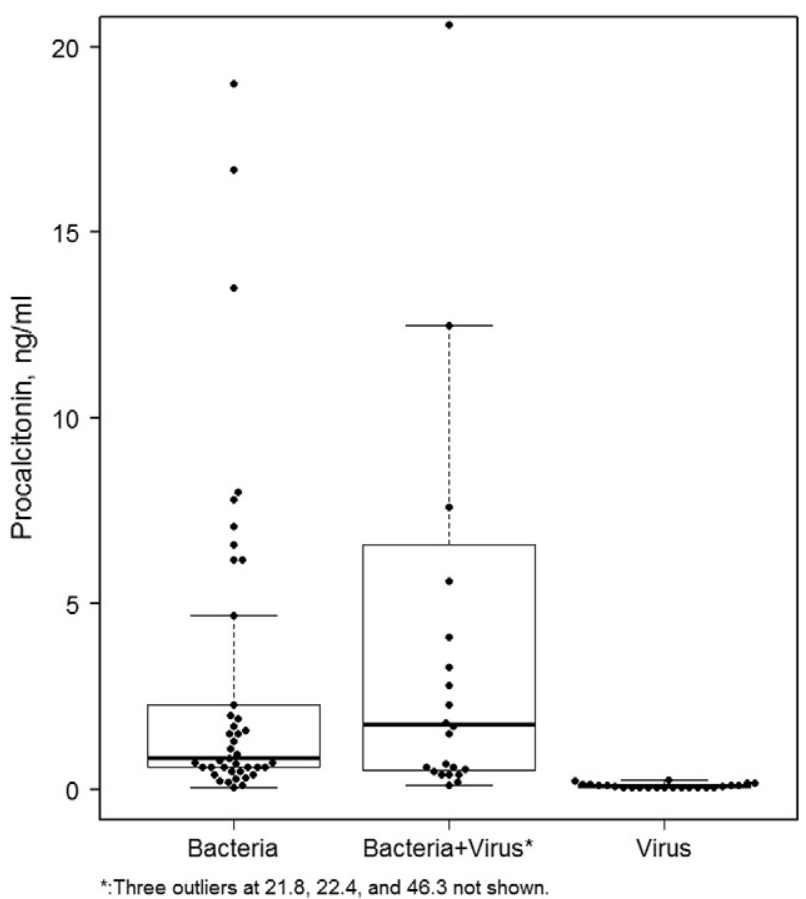

Fig. 2. Box plot of PCT values in patients with CAP caused by a virus, bacteria, or a combination of a virus and bacteria. The PCT values in patients with CAP due to bacteria alone or a virus plus bacteria are significantly higher than in patients with CAP caused only by a virus, $P=0.003$ 
Table 5

Influence of diagnostic results on antibacterial therapy (mean $\pm \mathrm{SD}$ ).

\begin{tabular}{|c|c|c|c|c|c|}
\hline & Diagnostic method & No. of patients & Cost of therapy $(\$)$ per 1000 patient-days & LOT $^{\ddagger}$ (days) per 1000 patient-days & DOT ${ }^{\ddagger}$ per 1000 patient-days \\
\hline \multicolumn{6}{|l|}{ Etiologic category } \\
\hline \multirow[t]{3}{*}{ Bacteria } & FilmArray & 21 & $9391 \pm 12270$ & $1274 \pm 920$ & $1549 \pm 775$ \\
\hline & Standard & 20 & $9771 \pm 9807$ & $1491 \pm 1463$ & $2326 \pm 2235$ \\
\hline & Combined & 41 & $9576 \pm 10999$ & $1380 \pm 1205^{+}$ & $1928 \pm 1682$ \\
\hline \multirow[t]{3}{*}{ Bacteria + virus } & FilmArray & 10 & $10482 \pm 11682$ & $1027 \pm 740$ & $1378 \pm 658$ \\
\hline & Standard & 14 & $20562 \pm 16383$ & $1851 \pm 20161$ & $2574 \pm 2100$ \\
\hline & Combined & 24 & $15362 \pm 15194$ & $1508 \pm 1638^{+}$ & $2076 \pm 1739$ \\
\hline \multirow[t]{3}{*}{ Virus } & FilmArray & 12 & $8392 \pm 8327$ & $841 \pm 294$ & $1388 \pm 804$ \\
\hline & Standard & 13 & $10442 \pm 6399$ & $848 \pm 219$ & $3056 \pm 4677$ \\
\hline & Combined & 25 & $9458 \pm 7304$ & $845 \pm 252^{++}$ & $2256 \pm 3458$ \\
\hline \multirow[t]{3}{*}{ No pathogen identified } & FilmArray & 16 & $5467 \pm 7259$ & $937 \pm 179$ & $1818 \pm 1203$ \\
\hline & Standard & 21 & $9023 \pm 10102$ & $1586 \pm 2058$ & $1403 \pm 449$ \\
\hline & Combined & 37 & $7485 \pm 9047$ & $1305 \pm 1572$ & $1583 \pm 871$ \\
\hline \multicolumn{6}{|l|}{ Pathogen } \\
\hline \multirow[t]{2}{*}{ Combined } & FilmArray & 59 & $8308 \pm 10165^{*}$ & $1053 \pm 657$ & $1560 \pm 895^{\neq}$ \\
\hline & Standard & 68 & $11890 \pm 11712^{* *}$ & $1472 \pm 1667$ & $2232 \pm 2574^{\neq \neq}$ \\
\hline
\end{tabular}

${ }^{\ddagger} \mathrm{LOT}=$ length of therapy; DOT = days of therapy

$+\mathrm{vs}++P=0.04$.

* $\mathrm{vs}^{* *} P=0.02$.

$\neq \mathrm{VS} \not \neq P=0.03$.

0.04. However, there was no difference in LOT between the FilmArray and Standard bundle patients with a viral infection.

The DOT was significantly lower in the FilmArray patients, $P=0.03$. For each of the etiologic categories with an identified pathogen, DOT was consistently lower in the FilmArray group. However, the difference was only significant in the bacteria + virus patients, $P=0.02$.

In 25 patients ( 13 standard and 12 FilmArray), the NP PCR detected a pathogenic virus without a concomitant bacterial pathogen, a clinical presentation consistent with a viral pneumonia, and a serum PCT level $\leq 0.1 \mathrm{ng} / \mathrm{mL}$. Nonetheless, discontinuation of the empiric antibiotics within 48 hours of test results occurred in only 8 of the 25 (32\%) patients. Despite the faster turn-around time for FilmArray patients, discontinuation of empiric antibiotics was almost identical ( 5 FilmArray patients and 3 standard patients).

\section{Discussion}

An etiologic pathogen was detected in $69 \%$ of the evaluable Standard bundle patients and $73 \%$ of the FilmArray bundle patients. Serum PCT levels separated patients with pure viral infections from patients with bacterial or mixed viral-bacterial pneumonia. The LOT was shorter for patients with pure viral infection, but the full potential for antibiotic de-escalation was not achieved.

In contrast, Musher, 2013 detected a bacterial pathogen in 28\% and a viral pathogen in $30 \%$ of patients. A pathogen was found in only $24 \%$ of CAP patients (Restrepo et al., 2008) if only bacterial cultures of blood and sputum plus urine antigen testing for L. pneumophila was performed. Various studies, adding PCR probes for atypical respiratory pathogens and viruses plus serologies, have reported diagnostic yields of 38\%, 53\%, $67 \%$ and $89 \%$ in CAP patients, respectively (Falsey et al., 2013; Jain et al., 2015; Johansson et al., 2010; Shibi et al., 2010).

Gadsby et al., 2016, collected sputum cultures in 323 PSI class 4 or 5 CAP patients. Retrospective PCR probes of the sputa identified one or more bacterial pathogens in $87 \%$ of the patients, and respiratory virus in $30 \%$. A mixture of bacterial and viral pathogens was found in $82 \%$ of the sputa containing a respiratory virus.

\subsection{Colonization vs infection by S. pneumoniae and S. aureus}

Depending on the detection method used, asymptomatic nasopharyngeal colonization of healthy adults by S. pneumoniae ranges from $8 \%$ to 22\% (Janoff and Musher, 2015; van Deursen et al., 2016). Further, approximately $20 \%$ (range $12-30 \%$ ) of otherwise healthy individuals are persistent nasal carriers of S. aureus (Que and Moreillon, 2015).
We accepted detection of S. pneumoniae by culture, urine antigen, or PCR as evidence of an etiologic pathogen, as opposed to colonization, if the patient had the clinical syndrome of CAP and an elevated serum level of procalcitonin. The same logic was applied to the detection of $S$. aureus by culture or nasal PCR. Only once was $S$. aureus interpreted as a solo pathogen; in 5 other patients $S$. aureus was detected along with either influenza or hMPV.

\subsection{Detection of S. pneumoniae by NP PCR}

Spik et al., 2013 increased detection of S. pneumoniae from $6.7 \%$ by sputum culture to $22.8 \%$ by PCR of sputum. Albrich et al., 2014 studied 222 South African HIV-positive adults with CAP. S. pneumoniae was cultured from sputum in $46 \%$ whereas the PCR was positive in either the NP aspirate or sputum in $67.1 \%$

\subsection{Low yield of blood cultures}

Only 2 of our 127 (1.6\%) evaluable patients had positive blood cultures which is lower than the 20 to $25 \%$ rate reported by Said et al. (2013), but similar to the $0.8 \%$ and $1.9 \%$ reported by Falsey et al. (2013) and Musher et al. (2013). In children, 118 blood cultures would need to be collected to identify one bacteremic patient. If blood cultures were limited to PSI class 4 or 5 patients and the immunocompromised, only 42 cultures would be needed to detect one positive (Andrews et al., 2015).

\subsection{Standard bundle vs FilmArray}

As summarized in Table 3, the standard viral PCR panel detected as many virus-infected patients as the larger (more viruses plus 3 bacteria) FilmArray panel. We suspect the lower yield occurred due to the low incidence of coronavirus, parainfluenza, Chlamydophila pneumoniae and Mycoplasma pneumoniae infections at the time of the study.

\subsection{Time to results and serum PCT level}

Our results demonstrate the ability to distinguish viral from bacterial infection within 2-8 hours of hospital admission, Table 4. It is thus possible to reconsider the need for respiratory isolation and antimicrobial therapy before the second scheduled dose of empiric antibacterials. 
4.6. Influence of rapid viral diagnostics and serum PCT levels on de-escalation

The absence of an elevated PCT level in a patient with a clinical syndrome compatible with a viral illness strongly suggests the absence of an active bacterial infection, and no benefit to empiric antibiotic therapy (Becker et al., 2008; Branche et al., 2015; Falsey et al., 2013; Gelfer et al., 2015; Gilbert, 2011, 2015; Schuetz et al., 2012, 2013).

Despite the presence of only a respiratory viral pathogen and normal PCT levels, empiric antibiotics were discontinued within 48 hours in only 8 of 25 (32\%) patients in this study, and 2 of 11 in that of Oosterheert et al. Branche et al., 2015 evaluated 151 patients hospitalized with lower, non-pneumonic respiratory tract infections, of whom 126 had a serum PCT level of $<0.25 \mathrm{ng} / \mathrm{mL}$ and $42 \%$ or $50 \%$ (?) had a viral pathogen detected. The result was a shorter duration of antibiotic therapy, $P=0.004$ and fewer patients discharged with a prescription for antibiotics, $P=0.002$.

\subsection{Limitations}

The study of only 127 patients is a major limitation, but replicates our previous pilot study of 59 evaluable patients (Gelfer et al., 2015).

We recognize the need to compare pathogen detection by PCR with detection in a matched control group. Asymptomatic carriage of S. pneumoniae and some respiratory viruses (e.g., rhinovirus) are much higher in children than adults (Self et al., 2016). Hence, detection in adults with an appropriate clinical syndrome supports the pathogenic role of detected potential pathogens. Studies either suggest or refute a correlation of pathogen density ("load") with invasive disease (Collins et al., 2016). Seroconversion is often the "gold standard" but not helpful during the acute illness (Albrich et al., 2014).

\section{Conclusion}

Our study results, and the work of others, support routine expansion of rapid diagnostic test bundles to include a rapid multiplex PCR platform for respiratory viruses to determine the etiology of CAP. The fast turnaround time of the FilmArray offers quick assistance to antibiotic stewardship activities. In addition, our data support the value of anterior nasal swabs for S. aureus PCR and NP swab for S. pneumoniae PCR.

Testing urine for the antigens of S. pneumoniae and L. pneumophila, serogroup 1 may ultimately prove duplicative to the next generation PCR platforms and/or next generation gene sequencing.

Sputum cultures are needed for in vitro antimicrobial susceptibility testing. The challenge is the collection of a suitable specimen before, or concomitant with, initiation of antibiotic therapy.

Due to the low yield of blood cultures, it seems reasonable to limit blood cultures to patients with the highest PSI scores (Class 4 and 5).

Low PCT levels support the absence of invasive bacterial disease. A low PCT level supports an interpretation of colonization when S. pneumoniae, H. influenzae, S. aureus or other potential bacterial pathogens are identified.

\section{Acknowledgments}

Thanks to Chris Siegenthaler for administrative support; Rob Denison for drug pricing; ED physicians, nurses and unit coordinators. Thanks for help with study design and data management: John Heffner, M.D. For advice on metrics of antibiotic use: Ron Polk.
This study was supported by a research grant from bioMerieux, Salt Lake City, UT, USA.

\section{References}

Albrich WC, Madhi SA, Adrian PV, Telles J-N, Parankos-Baccala G, Klugman KP. Genomic load from sputum samples and nasaopharyngeal swabs for diagnosis of pneumococcal pneumonia in HIV-infected adults. J Clin Microbiol 2014;52: 4224-9.

Andrews AL, Simpson AN, Heine D, Teufel RJ. A cost-effectiveness analysis of obtaining blood cultures in children hospitalized for community-acquired pneumonia. J Pediatrics 2015; 167:1280-6.

Becker KL, Snider R, Nylen ES. Procalcitonin assay in systemic inflammation, infection and sepsis: clinical utility and limitatons. Crit Care Med 2008;36:941-52.

Branche AR, Walsh EE, Vargas R, Hulbert B, Formica MA, Baran A, et al. Serum procalcitonin and viral testing to guide antibiotic use for respiratory infections in hospitalized adults: a randomized controlled trial. J Infect Dis 2015;212:1692-700.

Collins AM, Johnstone CMK, Gritzfeld JF, Banyard A, Hancock CA. wright AD et al. Pneumococcal colonization rates in patients admitted to a United kingdom Hospital with Lower Respiratory Tract Infection: a Prospective Case-Control study. J. Clinical Microbiology 2016;54:944-9.

Falsey AR, Becker K, Swinburne AJ, Nylen ES, Formica MA, Hennessey PA, et al. Bacterial complications of respiratory tract viral illness: a comprehensive evaluation. J Infect Dis 2013;208:432-41.

Gadsby NJ, Russell CD, McHugh MP, Mark H, Morris AC, Lowenson IF, et al. Comprehensive molecular testing for respiratory pathogens in community-acquired pneumonia. Clin Infect Dis 2016;62:817-23.

Gelfer G, Leggett J, Myers J, Wang L, Gilbert DN. The clinical impact of the detection of potential etiologic pathogens of community-acquired pneumonia. Diagn Microbiol Infect Dis 2015;83:400-6.

Gilbert DN. Procalcitonin as a biomarker in respiratory tract infection. Clin Infect Dis 2011;52:S346-50.

Gilbert DN. Where do we go from here (editorial). J Infect Dis 2015;212:1687-9.

Jain S, Self WH, Wunderink RG, Fakhran S, Balk R, Bramley AM, et al. Community-acquired pneumonia requiring hospitalization among U.S. adults. N Engl J Med 2015;373: 415-27.

Janoff EN, Musher DM. Streptococcus pneumoniae. In: Bennett JE, Dolin R, Blaser MJ, editors. Principles and Practice of Infectious Diseases. 8th ed. Philadelphia, PA: Elsevier Saunders; 2015. p. 2310-27.

Johansson N, Kalin M, Tiveljung-Lindell A, Giske CG, Hedlund F. Etiology of communityacquired pneumonia: increased yield with new diagnostic methods. Clin Infect Dis 2010;50:202-9.

Mandell LA, Wunderink RG, Anzueto A, Bartlett JG, Campbell GD, Dean NC, et al. Infectious Diseases Society of America/American Thoracic Society consensus guidelines on the management of community-acquired pneumonia in adults. Clin Infect Dis 2007;44: S27-72.

Musher DM, Roig IL, Cazares G, Stager CE, Logan N, Safar H. Can an etiologic agent be identified in adults who are hospitalized for community-acquired pneumonia: results of a one-year study. J Infect 2013;67:11-8.

Que Y-A, Moreillon P. Staphylococcus aureus. In: Bennett JE, Dolin R, Blaser MJ, editors. Principles and Practice of Infectious Diseases. 8th ed. Philadelphia, PA: Elsevier Saunders; 2015. p. 2237-71.

Restrepo MI, Motensen EM, Velez JA, Frei C, Anzueto A. A comparative study of community-acquired pneumonia patients admitted to the ward and ICU. Chest 2008; 133:610-7.

Said MA, Johnson HL, Nonyane BA, Deloria-Knoll M, O’Brien KL, AGEDD Adult Pneumococcal Burden Study Team, et al. Estimating the burden of pneumococcal pneumonia among adults: a systematic review and meta-analysis of diagnostic techniques. PLoS One 2013:8(4):e60273.

Schuetz P, Briel M, Christ-Crain M, Stolz D, Douadma L, Wolff M, et al. Procalcitonin to guide initiation and duration of antibiotic treatment in acute respiratory infections: an individual patient data meta-analysis. Clin Infect Dis 2012;55:651-62.

Schuetz P, Briel M, Mueller B. Clinical outcomes associated with procalcitonin algorithms to guide antibiotic therapy in respiratory tract infections. JAMA 2013;309:717-8.

Self WH, Williams DJ, Zhu Y, Ampofo K, Pavia AT, Chappell JD, et al. Respiratory viral detection in children and adults: comparing asymptomatic controls and patients with community-acquired pneumonia. J Infect Dis 2016;213:584-91.

Shibi F, Chazan B, Nitzan O, Flatau E, Edelstein H, Blondheim O, et al. Etiology of community-acquired pneumonia in hospitalized patients in northern Israel. Isr Med Assoc J 2010;12:477-82.

Spik VC, Beovic B, Pokorn M, Torkar AD, Vidmar D, Papst L, et al. Improvement of pneumococcal pneumonia diagnostics by the use of rt-PCR on plasma and respiratory samples. Scand J Infect Dis 2013:45:731-7.

van Deursen AMM, van den Bergh MR, Sanders EAM. Carriage of Streptococcus pneumoniae in asymptomatic community-dwelling elderly in the Netherlands. Vaccine 2016;34:4-6 